\title{
A Comparative Analysis Of Computer- Assisted Instruction And Traditional Lecture Instruction For Administration And Management Topics In Physical Therapy Education
}

\author{
Matthew R. Hyland, Mercy College, USA \\ Genevieve Pinto-Zipp, Seton Hall University, USA \\ Valerie Olson, Seton Hall University, USA \\ Steven W. Lichtman, Mercy College, USA
}

\begin{abstract}
Technological advancements and competition in student recruitment have challenged educational institutions to expand upon traditional teaching methods in order to attract, engage and retain students. One strategy to meet this shift from educator-directed teaching to student-centered learning is greater computer utilization as an integral aspect of the learning environment. The purpose of the present study was to assess the effectiveness of utilizing Computer-Assisted Instruction (CAI) to teach administration and management content in Physical Therapy (PT) education. It was hypothesized that CAI is equally effective for assimilation of information when compared to traditional lecture instruction (TLI). The sample consisted of third-year entry-level PT students enrolled in an Administration and Management course. Thirty-three of forty students who met the inclusion criteria consented to participate. Both the Mercy College and Seton Hall University IRB boards approved the project and all students signed informed consents. Participants were randomly assigned to the control (TLI, $n=16)$ or experimental (CAI, $n=17)$ group. Each participant completed a pretest on the material to be covered and a demographic survey to assess grade point average (GPA), gender, age and computer literacy. Students then attended the course in the designated medium and took a post-test at the end of the semester. There were no significant differences between the two groups for GPA, age or gender. Both groups showed significant improvement from pretest to post-test (51.5 \pm 12.7 to 80.6 $\pm 7.8 ; p<0.001)$, and (52.0 \pm 9.5 to 85.1 $\pm 6.1 ; p<0.001)$, respectively. No significant difference was found between the groups for baseline knowledge (52.0 \pm 9.5 vs. $51.5 \pm 12.7 ; p=0.905)$, final exam scores $(80.6 \pm 7.8$ vs. 85.1 $\pm 6.1 ; p=0.073)$ or final course grades $(90.2 \pm 3.0$ vs. $90.5 \pm 3.1 ; p=0.763)$. The hypotheses that CAI is equally effective for assimilation and retention of information presented in a professional management and administration PT class, when compared to TLI, was supported. Areas for further analysis include examining student satisfaction levels, work efficiency and long-term retention of material. With both teaching methods found to be equally effective, educators can utilize CAI to promote a student-centered experience for the high tech learners of today. Hiring faculty from remote locations to fill positions for which candidates are unavailable locally, and allowing instructors to teach multiple sections of the same course at different geographic campuses, is also possible with CAI. Additionally, if the instructor or student is absent or a lecture is not finished in the classroom, the material can be placed online. This new evidence supports the use of CAI in teaching administration and management material to $P T$ students, providing institutions of higher learning with an alternative teaching strategy to meet the needs of today's students.
\end{abstract}

Keywords: computer-assisted instruction, educational strategies, adult learning 


\section{INTRODUCTION}

$\mathcal{C}$

ontinued competition in student recruitment, concurrent with tremendous technological advancements, has challenged educational institutions to expand upon traditional teaching methods in order to attract and retain today's students. This paradigm shift has created an educational revolution in teaching methods, typified by centers for higher education moving away from educator-directed teaching to student-centered learning. ${ }^{5}$ Today's traditional undergraduate population exhibits unprecedented skills in computer literacy, while the graduate population is shifting toward an older student body characterized by full-time employees functioning on restricted time schedules and in specific geographic locations. ${ }^{15,17}$ Both the undergraduate and graduate student demands a learning environment that facilitates better acquisition of higher cognitive learning, such as critical thinking skills. ${ }^{18}$ Consequently, curriculum changes and instructional revisions need to occur so that campus climates meet the needs of today's student body in an attempt to foster improved student growth. ${ }^{18}$ Greater computer utilization as a teaching strategy may help educators meet the needs of today's students in higher education.

Supplementing or replacing the traditional classroom model with the computer is known as computerassisted instruction (CAI). It is also referred to as distance learning, on-line instruction, computer-assisted learning, blended learning, asynchronous learning, web-based instruction, cyber education, or computer enhanced instruction. ${ }^{19}$ The intent of CAI is the ability to offer an alternative educational medium in a non-traditional manner with the freedom to customize instructions to better suit a diverse population. ${ }^{9}$ Computer-assisted instruction generally consists of three main forms: as a course supplement, as a hybrid (a.k.a. computer enhanced), or as a replacement. Numerous disadvantages of CAI have been cited, including: high start up costs, lack of adequate software, an emphasis on technology versus teaching, changes in teacher / learner roles, and the inability to reach all learning styles, especially learners who may not thrive in this type of learning environment. ${ }^{6,20}$ Frequently cited advantages of CAI include: the ability to use a varied instructional event, create individualized instruction, create increased accessibility, promote time efficiency, enhance overall instructional effectiveness, provide consistency, increased convenience, promote student privacy, and the development of critical thinking skills. ${ }^{6,20}$ Given the noted advantages of CAI it is understandable why for the past several years; online enrollments have been growing substantially faster than overall higher education enrollments. The 9.7 percent growth rate for online enrollments far exceeds the 1.5 percent growth of the overall higher education student population. ${ }^{1}$ The Sloan C Survey (2007) reported that almost 3.5 million students ( $20 \%$ of all U.S. higher education students) were taking at least one online course during the fall 2006 term; a nearly 10 percent increase over the number reported the previous year. ${ }^{16}$

Use of CAI has been studied in non-healthcare professional education, but no significant difference in the depth and breadth of knowledge between CAI and traditional learning instruction has been noted for courses in physical education, ${ }^{24}$ business ${ }^{31}$ or economics ${ }^{19}$. Konukman et al did show that the rate of knowledge acquisition was faster for CAI learning group compared to a traditional learning group. ${ }^{24}$

Computer-assisted instruction has been studied in many health care programs such as physiology ${ }^{28}$ radiology ${ }^{22}$, anatomy ${ }^{30}$ and neuroanatomy. ${ }^{27}$ Consistent with non Healthcare programs of study, results yielded no statistical significance for learning between the groups. Together, these studies indicate that CAI is as effective a teaching method as the traditional classroom method for initial acquisition of information. However, when assessing long term learning, results indicate that while initial learning of material was comparable between the groups, retention of the learned material was improved when using CAI. ${ }^{28}$

The use of CAI in physical therapy programs has been rapidly expanding over the past decade. In 1994, Kosmahl, ${ }^{25}$ reported that only $30 \%$ of all accredited entry-level physical therapy programs in the US utilized CAI in some form. A survey performed in 2002 by Phillips-Simpson ${ }^{29}$ identified that $83 \%$ of the 186 accredited entry-level physical therapy programs in the US required students to access the web to complete assignments in several or all courses. Additionally the survey indicated that $68 \%$ utilized web boards for communication with students, $71 \%$ utilized CAI in specific coursework and $8 \%$ reported they were planning on implementing it within a year. Of the respondents 95\% were in favor of online instruction in entry-level physical therapy programs; while 79\% felt that it should be limited to certain types of courses, including administration, education, ethics and pathology, all of which are courses without clinical hands-on practice. ${ }^{29}$ In 2003 , Erickson ${ }^{14}$ showed via survey that $80 \%$ of the responding PT programs utilize CAI for specific coursework (up 9\% from the previous year). The most common topics in 
which CAI was used exclusively online were: Introduction to PT, Administration/ Management, Anatomy and Measurement, Assistive Technology, and Healthcare Delivery in the United States. ${ }^{29}$ In 2004, Hyland and Willis ${ }^{21}$ surveyed the directors of physical therapy programs regarding the use of CAI within their Administration and Management course. Results identified that $96 \%$ of the respondents were using some form of CAI within their program; however, only 52.8\% were utilizing CAI within Administration and Management courses. The study also assessed the qualifications of those teaching Administration and Management. The highest degree earned by the instructor was: Master's $44 \%$, Doctorate $34 \%$, and Bachelors $22 \%$. The majority of instructors were non-practicing full time faculty (78\%). Years of teaching experience in Administration and Management for all respondents were: more than eight years $44 \%$, six to eight years $12 \%$, three to five years $27 \%$, and less than three years $17 \%$.

While the expanding use of CAI in physical therapy education has been well documented, few studies exist demonstrating its effectiveness. Kinney et $\mathrm{al}^{23}$ studied the efficacy and efficiency of CAI for students learning evaluation and treatment skills for carpal tunnel syndrome. Results showed no significant differences in pretest/posttest scores between the groups; however, the CAI group completed the case assignment 30 minutes (24\%) quicker than the interactive (traditional) group. English et $\mathrm{al}^{13}$ studied outcomes within a physical therapy program at the University of Kentucky. This institution offered physical therapy at two different geographic locations 150 miles apart using the CAI approach for one cohort and TLI approach for the other cohort. Exam scores and course evaluation scores were compared, and no statistical significance was found. Plack ${ }^{30}$ compared first year physical therapy students who took gross anatomy via CAI and lab (cadaver prosections), to those who took it in the traditional lecture and lab fashion. The results showed no significant difference between the groups on any grading criteria. This study provides further support for the hypothesis that CAI is a comparable teaching tool to traditional classroom learning. Bukowski ${ }^{8}$ studied three alternative methods of instruction (lecture/lab, CAI, self-study) in a human gross anatomy course. There were no significant differences between any of the groups for final course grade or time spent on course material. There was also no significant difference between any of the groups for future performance in the PT curriculum, on affiliations, or on the licensure exam. These studies provide further evidence demonstrating that as a teaching tool, CAI is equally as effective as traditional classroom teaching and has comparative student satisfaction levels. It is also consistent with previous research (Konukman et al $^{24}$ ) identifying CAI as a faster learning medium when compared to TLI.

The governing body of the Physical Therapy profession, the American Physical Therapy Association, supports the use of CAI. Over the past several years they have taken a formal position regarding online education. The APTA has begun to implement various forms of CAI through online continuing education, news releases, and publications. On a Chapter (state) level, Texas has begun to utilize CAI in the certification of Clinical Instructors (CI), now making it possible for $\mathrm{CI}$ in rural, remote areas to receive the same on-site training as their colleagues in urban regions. $^{32}$

From an educational standpoint, the Commission on Accreditation in Physical Therapy Education (CAPTE) has adopted a position paper on CAI titled "Principles of Good Practice for Distance Learning." 12 The position paper establishes the criteria for using CAI, and states that programs should be reviewed against the 'Principles of Good Practice'. While CAPTE has published this formal position on CAI, there has also been a change in the entry-level educational requirement for physical therapy as part of the initiative, "Vision 2020.",2,3 Presently, all PT programs are required to be at a minimum of a Masters level curriculum with the established vision of a Doctorate in Physical Therapy [DPT] being the minimum by the year 2020. With the advancement of the Doctor of Physical Therapy requirement PT program curriculum will be expanded and modified to meet today's health care needs. Specifically, a course in administration and management is noted as essential practice. ${ }^{2,3}$ While the requirement of including administration and management material is important as an entry-level skill, a dearth of qualified instructors exists to teach this course material, and thus poses an issue for educational programs. ${ }^{21}$

Over the past decade in order to meet the needs of today's health care professional and student body educational programs, specifically physical therapy, have expanded the use of CAI within their curricula. With this growth, programs must be careful to implement technology such as CAI without compromising student learning. Physical therapy programs must evaluate how they will best utilize CAI within their curriculum in order to attract, stimulate, engage and retain today's technology driven students. Although computer-assisted instruction continues to become more prevalent in physical therapy education, there is little evidence supporting its global use in physical 
therapy education. The effectiveness of CAI in clinical and non-clinical coursework needs to be assessed as well. Additionally, with a change in the entry-level requirements for physical therapy, a teaching conflict exists as faculty members who teach for example administration and management material may have little practical background in the subject matter, or conversely, practicing administrators may have little teaching experience. The use of CAI attempts to bridge the gap between two seemingly different educational problems: the lack of evidence regarding CAI in physical therapy education, and the lack of qualified instructors teaching administration and management topics within programs. Therefore the purpose of this study was to assess the effectiveness of teaching administration and management content in physical therapy education utilizing computer-assisted instruction. It was hypothesized that CAI will be equally effective for assimilation of information (measured by earned grade on final exam and final course grade) presented in a professional management and administration class when compared to traditional lecture instruction (TLI).

\section{METHODS}

\section{Subjects}

A sample of convenience was drawn from third year, master's degree level physical therapy students at Mercy College (Dobbs Ferry, NY). Subjects were selected based on the following criteria: Inclusion: 1. enrolled as a graduate student in the Mercy College Physical Therapy program; 2. enrolled in PHTR620, Administration and Management of Physical Therapy in 2004; 3. accepted randomization into either the control or experimental group; 4. self declared proficient in Mercy College's online computer media (Campus Pipeline-Web CT); 5. presence of computer access. Exclusion: 1. refusal to participate in the study. Forty students were enrolled in PHTR620 in 2004 and 33 consented to participate in the study.

\section{Research Design}

The study utilized a prospective, experimental, randomized, single factor, pretest /post-test design. The project was approved by both the Mercy College and Seton Hall University Institutional Review Boards, and all students signed appropriate informed consents prior to participation.

\section{Procedures}

For recruitment, the primary researcher met with all 40 students registered for PHTR620 prior to the semester and described the study to the potential participants, who were then provided an opportunity to ask questions. Once questions were answered, the primary researcher left the classroom, and a Mercy College faculty member not associated with the study obtained signed informed consent forms from the entire class. On the informed consent form, two signature lines (one agreeing to consent and the other refusing participation) were available. In addition to the informed consent, each potential participant completed a pretest on the material to be covered in PHTR620 and a demographic survey. The demographic survey consisted of 24 questions. The survey was adapted from a questionnaire developed by Davis. ${ }^{11}$ The purpose of the survey was to provide demographic information (GPA, gender, age) assess computer literacy and measure student attitude toward CAI. Each student submitted their paperwork to the research assistant and left the classroom. The research assistant then separated those students who had consented from those who did not.

The students who consented were randomly assigned via lottery, to either the control (Traditional Lecture Based Instruction (TLI), n=16) or experimental group (CAI, n=17), and their paperwork, which was coded to assure anonymity, was given to the primary researcher. Those who did not consent to participate in the study were informed by the research assistant to attend the traditional lecture instruction. This selection procedure was utilized to avoid any possible coercion as perceived by the students. Although it was known which students were in the CAI group, it was not known by either the primary researcher (course instructor) or those in the classroom portion who had consented to participate in the study and those who had not. Thus the primary investigator was blinded to participation and assignment. Students then attended the course in the designated medium and at the end of the semester, all students took a post-test. 
The independent variable (teaching methodology) was studied during an Administration and Management of Physical Therapy (PHTR620) course taught in 2004. PHTR620 was a required class within the master's level Physical Therapy Program at Mercy College. The Mercy College Physical Therapy program is a weekend curriculum that was taught in a lifespan model. PHTR620 was a one semester long class that met on nine Friday nights throughout the semester for a total of four hours per meeting. The independent variable was administered in two levels, traditional lecture based instruction (TLI) and CAI.

The TLI group was taught in a traditional classroom, and material was disseminated in a lecture style format utilizing Power Point overheads as a teaching medium. Lecture supplements included study questions and lecture outlines. Students had the opportunity to ask questions throughout the semester, either in class or scheduled meeting, allowing for more in-depth explanation of topic material if needed. Within this format, students were also allowed to give personal experiences regarding the material. Covered topics included management and administration issues in physical therapy.

The CAI group had unlimited access to the course web site (Campus Pipeline) throughout the semester. The topics covered each week were the same for both groups. The CAI group received the professor's notes online in a lecture style format for the class to read. Specific examples were included within the notes to help the students grasp the material. Additionally, they received the same Power Point presentation, study questions, and lecture outline as the control group. The same assignments, consisting of readings and case studies, were required for both groups. Consistent with the classroom group, students in the CAI group were able to ask questions of the instructor via email or through threaded online discussion and share personal experiences also through threaded online discussion. The only difference between the TLI and CAI groups were the utilization of a computer in the CAI group and the absence of face to face dialogue.

Pretest and post-test examinations were comprised of 25 and 50 multiple choice questions respectively, with one answer and three distracters per question. The tests were scored by the percentage of questions answered correctly. The pre-test was administered prior to any form of education in PHTR620, serving as a tool to assess the pre-intervention knowledge of the participants. This assessment determined the equality of knowledge between the groups in the test areas before the study began. Both the pretest and the post-test were drawn from a bank of questions that have been utilized for PHTR620 from 1996 to 2004. This bank was comprised of approximately 200 questions and was categorized according to Bloom's Taxonomy in order to assure a variety of necessary learning strategies ranging from memorization to the ability to critically assess material. ${ }^{7}$

To establish reliability of the examinations, an analysis of variance (ANOVA), with Tukey post hoc, was performed on the test years 1997-2003 (1996 and 2002 were omitted due to the fact that different testing procedures and exam formats were used in those years). The total sample number for the 6 assessed years was 168, with an individual class mean of 28. The ANOVA revealed the only significance difference in score was 1997 compared with $1998(7.19 \pm 1.54 ; \mathrm{p}=0.00), 1999(6.91 \pm 1.47 ; \mathrm{p}=0.00)$ and $2000(8.02 \pm 1.50 ; \mathrm{p}=0.00)$; and 2000 compared with $2001(5.18 \pm 1.47 ; \mathrm{p}=0.01)$ and $2003(5.10 \pm 1.56 ; \mathrm{p}=0.02)$. There are many possible reasons a particular class may be stronger statistically than another on a given exam; however, the overall homogeneity of the exam scores year to year indicates an overall excellent level of reliability of the question bank. Content and context validity of the two tests were established together via the use of three content experts. These individuals were identified by the primary researcher based upon their teaching background and knowledge of the material covered in PHTR620. All three were full time faculty at their institutions, currently teaching similar material within their curriculum. The test questions, along with the course syllabus and lecture materials, were sent to the content experts. The course content and lectures were reviewed. Test questions were assessed for validity, as well as rated according to Bloom's Taxonomy. Based upon the feedback from the content experts, it was determined that the material covered in PHTR620 both complied with CAPTE requirements and was appropriate for a graduate level course in a PT curriculum.

Course Grade: The final course grade was comprised of the following evaluative criteria: final exam (25\%), final project (20\%), health and wellness assignment (20\%), ethics paper (15\%), and two case studies (10\% each). The final project required students to create a business plan for a fictional physical therapy practice they wanted to establish. The health and wellness project required that students identify a health/ wellness need in a community, 
then develop and complete a plan to address that need. The course coordinator collected the assignments, and after giving them to the research assistant to code, graded each assignment. The ethics paper was based on the nonfictional case of Christine deMeurers. ${ }^{4}$ Students were required to write a 3-4 page paper discussing the case from an ethical perspective. The first case study was based on "The Associate Controller and Directors."26 The second case was created by the course coordinator of PHTR620 and was based upon a fictitious private practice in a local county that is undergoing a period of change. The previously successful practice is beginning to experience financial difficulties and has decisions to make regarding the future of the practice. Students were provided a series of six questions to answer regarding the case as if they were hired by the practice as consultants.

\section{Data Analysis}

Subject demographic information (age, gender, GPA, distance from Mercy College, home computer access, internet access, previous participation in CAI, and interest in taking a course via CAI) are reported as a percentage of respondents for each established category. To determine if there were significant differences between the students attending in the spring and fall semesters, final exam grade and final course grade were compared using unpaired Student's t-tests. To determine if the groups were equivalent at baseline, demographic characteristics of subjects in the CAI group were compared to the TLI group using unpaired Student's t-tests (GPA and age) and Chi Square analysis (gender).

To determine if CAI was equally effective for assimilation and retention of information compared to the TLI group, between group differences of the pretest and post-test and the final grades for the groups were compared using unpaired Student's t-tests. Paired Student's t-tests were utilized to determine differences within the groups from pre-test to post-test. Unpaired t-tests revealed no significant difference for final exam grade $(83.7 \pm 5.0$ vs. $81.7 \pm 9.1 ; \mathrm{p}=0.478)$ or final course grade $(90.2 \pm 3.0$ vs. $90.5 \pm 3.1 ; \mathrm{p}=0.733)$ between the students in the spring and fall semester, therefore their data, were pooled for all final comparisons.

Power analysis was based upon a pilot study and determined that 32 subjects were needed to achieve $80 \%$ power. With 33 out of the possible 40 participating the minimum threshold was met. SPSS version 12.0 was used for all analyses, with alpha level set at $\leq 0.05$.

\section{RESULTS}

\section{Demographics}

Three individuals did not fill out the demographic survey correctly, therefore their information was omitted, reducing the sample number to $30(\mathrm{CAI}=15$, TLI=15). There were no significant differences between the two groups with regard to grade point average (GPA) $(\mathrm{p}=0.852)$, age $(\mathrm{p}=0.095)$, and gender $(\mathrm{p}=0.217)$ (see Table 1$)$. Descriptive demographic information regarding computer/internet/CAI knowledge is found in Table 2.

\section{Pretest/Post-test Scores}

Both the CAI and TLI groups showed a significant improvement in test scores from pretest to post-test (51.5 \pm 12.7 to $80.6 \pm 7.8 ; \mathrm{p}<0.001)$, and $(52.0 \pm 9.5$ to $85.1 \pm 6.1 ; \mathrm{p}<0.001)$ respectively. There was no significant difference between the CAI and TLI groups for baseline knowledge (52.0 \pm 9.5 vs. $51.5 \pm 12.7 ; \mathrm{p}=0.905)$. There was no significance difference between the CAI and TLI groups for final exam scores $(80.6 \pm 7.8$ vs. $85.1 \pm 6.1 ; \mathrm{p}=0.073)$ (see Figure 1). 


\begin{tabular}{|c|c|c|}
\hline Demographic & CAI (\%) & TLI (\%) \\
\hline \multicolumn{3}{|l|}{ Gender } \\
\hline Male & 66.6 & 40.0 \\
\hline Female & 33.3 & 60.0 \\
\hline \multicolumn{3}{|l|}{ Age (years) } \\
\hline $45-50$ & 26.6 & 0.0 \\
\hline $40-44$ & 6.7 & 13.3 \\
\hline $35-39$ & 6.7 & 13.3 \\
\hline $30-34$ & 40.0 & 26.6 \\
\hline $25-29$ & 13.3 & 33.3 \\
\hline $20-24$ & 6.7 & 13.3 \\
\hline \multicolumn{3}{|l|}{ GPA } \\
\hline $3.8-4.0$ & 6.7 & 0.0 \\
\hline $3.5-3.7$ & 53.3 & 66.6 \\
\hline $3.2-3.4$ & 33.3 & 20.0 \\
\hline $2.9-3.1$ & 6.7 & 13.3 \\
\hline \multicolumn{3}{|c|}{ Distance from Mercy (min) } \\
\hline$>120$ & 0.0 & 26.6 \\
\hline $90-120$ & 0.0 & 0.0 \\
\hline $60-90$ & 40.0 & 6.7 \\
\hline $30-60$ & 33.3 & 40.0 \\
\hline$<30$ & 26.6 & 26.6 \\
\hline \multicolumn{3}{|c|}{ Own a home computer } \\
\hline Yes & 100.0 & 93.3 \\
\hline No & 0.0 & 6.7 \\
\hline \multicolumn{3}{|c|}{ Have easy internet access } \\
\hline Yes & 100.0 & 100.0 \\
\hline No & 0.0 & 0.0 \\
\hline \multicolumn{3}{|c|}{ Have taken CAI course } \\
\hline Yes & 53.3 & 40.0 \\
\hline No & 46.7 & 60.0 \\
\hline \multicolumn{3}{|c|}{ Interested in taking CAI } \\
\hline Yes & 93.3 & 93.3 \\
\hline No & 6.7 & 6.7 \\
\hline
\end{tabular}

*Three individuals $(\mathrm{CAI}=2, \mathrm{TLI}=1)$ did not fill out the demographic survey correctly. Their results were omitted, leaving a total $n=30$ 


\section{Question}

Table 2: Subject Characteristics: Computer Knowledge

How do you rate your overall computer knowledge?

$\begin{array}{lll}\text { Expert } & 6.7 & 0.0 \\ \text { Novice } & 60 & 86.6 \\ \text { Little experience } & 32 & 13.3 \\ \text { No experience } & 0.0 & 0.0\end{array}$

How many hours per week do you spend using the computer?

$\begin{array}{lll}<1 & 13.3 & 0.0 \\ 1-7 & 33.3 & 60.0 \\ 8-14 & 33.3 & 33.3 \\ >14 & 20.0 & 6.7\end{array}$

I can easily compose documents on a computer.

$\begin{array}{lll}\text { Strongly agree } & 40.0 & 46.7 \\ \text { Agree } & 46.7 & 53.3 \\ \text { Disagree } & 13.3 & 0.0 \\ \text { Strongly disagree } & 0.0 & 0.0\end{array}$

I can save documents without difficulty on the computer.

$\begin{array}{lll}\text { Strongly agree } & 53.3 & 66.6 \\ \text { Agree } & 46.7 & 26.6 \\ \text { Disagree } & 0.0 & 6.7 \\ \text { Strongly disagree } & 0.0 & 0.0\end{array}$

I can easily install programs onto a computer.

Strongly agree $\quad 40.0 \quad 26.6$

$\begin{array}{lll}\text { Agree } & 33.3 & 6.7\end{array}$

$\begin{array}{lll}\text { Disagree } & 6.7 & 60.0\end{array}$

$\begin{array}{lll}\text { Strongly disagree } & 20.0 & 6.7\end{array}$

I can easily send email messages to others using the Internet.

$\begin{array}{lll}\text { Strongly agree } & 66.6 & 73.3 \\ \text { Agree } & 33.3 & 26.6 \\ \text { Disagree } & 0.0 & 0.0 \\ \text { Strongly disagree } & 0.0 & 0.0\end{array}$

I am able to send documents as attachments through the Internet without difficulty.

$\begin{array}{lll}\text { Strongly agree } & 46.7 & 53.3 \\ \text { Agree } & 53.3 & 33.3 \\ \text { Disagree } & 0.0 & 13.3 \\ \text { Strongly disagree } & 0.0 & 0.0\end{array}$

I am comfortable in using the Mercy College Pipeline system.

$\begin{array}{lll}\text { Strongly agree } & 53.3 & 33.3 \\ \text { Agree } & 40.0 & 60.0 \\ \text { Disagree } & 6.7 & 0.0 \\ \text { Strongly disagree } & 0.0 & 6.7 \\ \text { ily conduct searches for information on the Internet. } & \\ \text { Strongly agree } & 53.3 & 33.3 \\ \text { Agree } & 40.0 & 60.0 \\ \text { Disagree } & 6.7 & 6.7 \\ \text { Strongly disagree } & 0.0 & 0.0\end{array}$

I can download information from the Internet without difficulty.

$\begin{array}{lll}\text { Strongly agree } & 46.7 & 33 \\ \text { Agree } & 46.7 & 66.6 \\ \text { Disagree } & 6.7 & 0.0 \\ \text { Strongly disagree } & 0.0 & 0.0\end{array}$

*Three individuals $(\mathrm{CAI}=2, \mathrm{TLI}=1)$ did not fill out the demographic survey correctly. Their results were omitted, leaving a total $n=30$ 


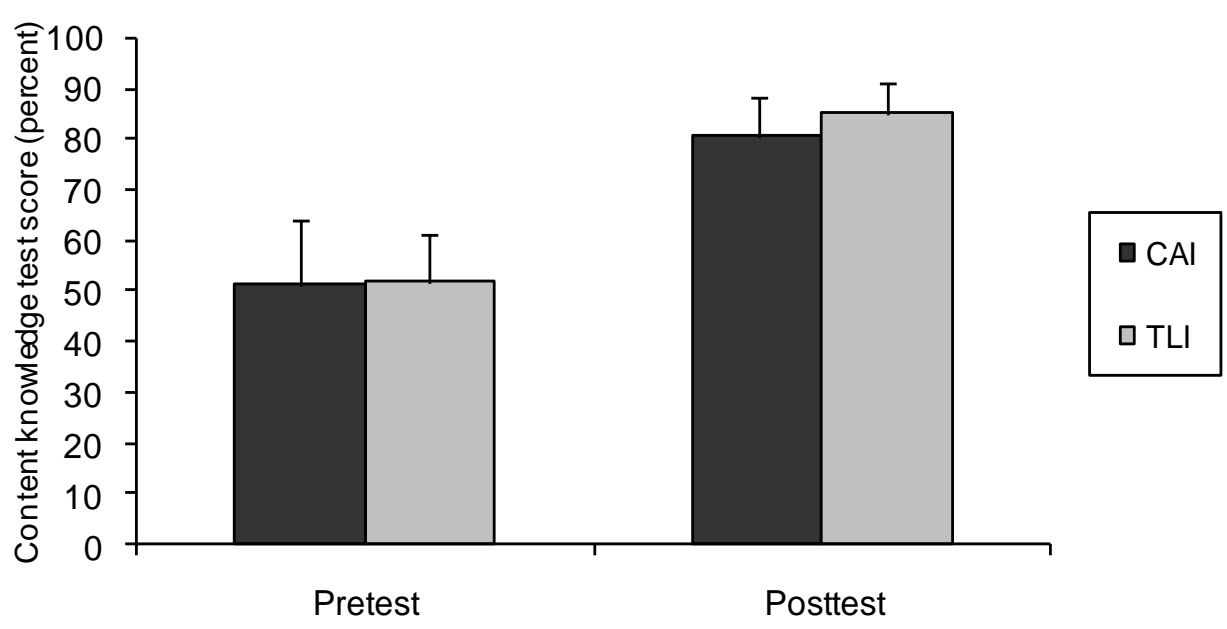

\section{Final Course Grade}

There was no significant difference between the CAI and TLI groups for final course grades $(90.2 \pm 3.0$ vs. 90.5 $\pm 3.1 ; \mathrm{p}=0.763$ ) (see Figure 2).

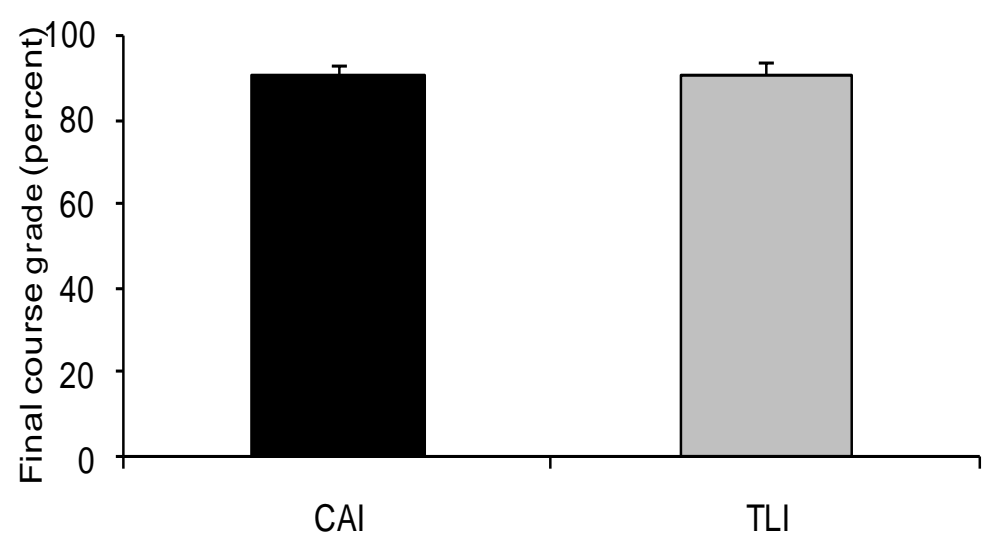




\section{DISCUSSION}

The results of this study indicate that both the CAI and TLI groups showed similar levels of knowledge acquisition with no significant difference found between the groups. These findings are consistent with previous studies within the field of healthcare. ${ }^{8,22,28}$ They are also consistent with previous studies specifically in Physical Therapy. ${ }^{8,23,30}$ Therefore, students' ability to learn didactic information in this non-clinical course using an alternative model (CAI) was supported in this study, and is consistent with previous research using the criteria of final exam score and course grade.

Students' success in the classroom does not necessarily equate to their satisfaction with a teaching strategy. This study did not formally assess satisfaction levels; however, subjective student information obtained on the course evaluation is consistent with previously published research. Hirschheim ${ }^{20}$ performed an open-ended questionnaire survey $(\mathrm{n}=25)$ to assess quality of learning. He accepted, based upon previous literature that no significant differences existed in learning as measured through testing between the teaching mediums. Consequently, the study focused on students' self-reported quality of learning or satisfaction levels. His results showed an overwhelming positive response that CAI was more convenient $(76 \%)$ than TLI. In contrast, he also found that $74 \%$ of respondents felt like "they had missed out on something" because they had not attended the classroom sessions. ${ }^{20}$ The feeling of "missing out" is prevalent throughout the course evaluations of the CAI group in the present study. The Mercy College course evaluations consist of multiple open-ended questions regarding the course and the instructor. The subject of one such question is "Things I did not like about the class." In this section 12 of the 17 students $(71 \%)$ reported some variation on the theme of "missing out on something that the classroom students were getting."

The results of the present study need to be viewed in light of several limitations. The sample was collected from a non-traditional (weekend) PT program and may not be representative of the majority of programs in the United States. For example, the gender distribution of the study population was $57 \%$ female and $43 \%$ male, as compared to a national PT student population of $73 \%$ female and $27 \%$ male during the same time frame. Additionally, discrepancies in ethnicity between the study sample and the national student population and APTA member profile also exist. The study sample was comprised of $36.0 \%$ minority, as compared to $17.0 \%$ in physical therapy programs nationally. Other unique attributes of the study sample include being $100 \%$ commuters, with the majority commuting 1 hour, and a more mature population, with $66 \%$ being over the age of 30 . This information may indicate that the study population was not representative of the general PT student. However, the study population was consistent with the qualifications for acceptance into PT programs. In 2004, a task force established by the Education Section of the APTA presented a set of recommendations describing a set of "core" requirements for admission into PT programs. At the time of admission for the subjects who participated in the present study, Mercy College met all recommended guidelines with the exception of requiring standardized testing, such as the GRE's. While the individuals applying to PT schools may be unique in their personal attributes, these recommended requirements create a more homogeneous applicant pool, due to similarities in their educational qualifications. Additionally, PT curricula are overseen by the Commission on Accreditation of Physical Therapy Education (CAPTE), thus making them uniform in the information required to be presented and learned. Finally, upon completion, graduates must successfully pass the licensure exam prior to practicing independently. Mercy College's passing rate for first time test takers in 2004-2005 (which would be inclusive of the study sample) was above the New York State average and comparable to the national average. While the study sample demographic make-up was different than the national student population, they were similar in their educational background, information taught, and information learned as evident on the licensure exam, thus creating a representative sample of PT students. The small sample size is an acknowledged limitation $(n=33)$. The course material covered in Administration and Management and the criteria used for grading may also be a threat to the study. While CAPTE outlines content areas to be covered by programs, there is variability in how the material is presented, as well as in what depth, and which assessment tools used. These noted limitations to the sample create threats to the external validity.

Threats to internal validity were also present with regard to the testing and grading criteria used. The CAI group's outcomes may have been due to the impact of the computer itself as opposed to their actual ability to learn. This was controlled for through the demographic survey. The survey included questions regarding students' comfort 
levels with computers and the online Mercy College Pipeline system. The entire CAI group reported having computer experience, and identified that they were able to compose emails, send documents, save documents and were comfortable with the Pipeline system. To control for test question threats, no questions on the pre-test were repeated on the post-test. Finally, there was little ability to control for students in both classes communicating with each other outside of the PHTR620 class. These out of class communications should not have had an impact on the outcome of the study because the use of or lack of use of the computer to obtain information covered in the class was the point of interest. All students received the same material and had the same assignments; therefore, any discussions or interactions that occurred were outside the scope of material being presented by the instructor.

While the present research supports the use of CAI, it raises new issues for further analysis. As institutional consumers, student satisfaction levels are very important for recruitment and retention. Evaluating efficiency with regard to time required for comprehending material, completing homework assignments, or preparing for the final exam. Outcome data in this arena may alter the workload given in a particular medium over the course of a semester. Additional long term follow-up studies assessing retention of presented and learned material between the two groups on the subject matter is important. Generational studies to assess ability and satisfaction, determining whether a certain age demographic has a propensity to perform better or receive higher gratification in a certain medium is also important.

The effective use of CAI affords many new possibilities to institutions of higher education. From an educational standpoint, it allows hiring faculty from remote locations to fill positions for which suitable candidates are unavailable locally. It also allows an instructor to teach multiple sections of the same course at different geographic campuses. Additionally, it creates new marketing strategies for institutions to attract, stimulate, engage, and retain today's students. These options benefit not only the institution, but ultimately, the students as well. From the students' perspective, CAI allows them to use a medium with which they are comfortable. Finally, it allows for more continuity in the learning environment. For example, if an instructor cannot finish a lecture, the material can be completed or supplemented via CAI. If the instructor or student is absent due to illness or emergency, the material can be placed online so that no one falls behind.

The purpose of the present study was to assess the effectiveness of teaching administration and management content in physical therapy education utilizing CAI. The effectiveness of teaching in a CAI format has three facets: the instructor's ability to teach, the instructor's ability to teach in an online medium, and the students' ability to learn in this medium. This study focused on the third facet, giving educational institutions more options in addressing the first two: the instructor's ability to teach, and his or her ability to teach in an online medium. In conclusion, the present study supports the hypotheses that CAI will be equally effective for assimilation and retention of information presented in a professional management and administration class when compared to TLI. This new evidence supports the use of CAI in the teaching of administration and management material to physical therapy students, providing institutions of higher learning with an alternative teaching strategy to meet the needs of today's students and marketplace as a whole and opens the door to assess CAI effectiveness in other non-clinically based and clinically based courses.

\section{ACKNOWLEDGEMENT} project.

We offer great appreciation to the staff at Rye Physical Therapy \& Rehabilitation for their support of this

\section{AUTHOR INFORMATION}

Dr. Matthew Hyland is a faculty member at Mercy College in the Department of Physical Therapy. He received his $\mathrm{PhD}$ from Seton Hall University Department of Graduate Programs in Health Sciences in 2007. He is a licensed physical therapist. Dr. Hyland teaches coursework related to management.

Dr. Pinto Zipp is an Associate Professor and Chair of the Department of Graduate Programs in Health Sciences at Seton Hall University. She received her EdD from Teachers College Columbia University in 1996. She currently teaches management of neuromuscular problems in the Doctor of Physical Therapy program. Her research interests 
focus on, a) effects of performing dual tasks on walking performance and postural sway in children and adults, and b) curriculum design issues including the use of mind mapping and video based cases in professional education for the promotion of clinical decision making skills.

Dr. Valerie Olson is an Associate Professor in the Department of Graduate Programs in Health Sciences at Seton Hall University. She received her PhD from Seton Hall University Department of Graduate Programs in Health Sciences in 2000. She is a licensed physical therapist. Dr. Olson teaches coursework related to curriculum development and strategic planning. She conducts research in the areas of teaching and learning and cultural relations.

Dr. Steven Lichtman is an Assistant Professor in the Physical Therapy Department at Mercy College. He is a licensed physical therapist. Dr. Littman teaches coursework related to research methods.

\section{REFERENCES}

1. Allen E, Seaman J. Online Nation: Five years of growth in online learning, Sloan C Foundation. Available from: http://www.sloan-c.org/publications/survey/pdf/online nation.pdf . Accessed March 12, 2008.

2. APTA House of Delegates endorses a vision for the future. Available from http://www.apta.org/news/news_releases/news_archives/visionstatementrelease. Accessed on August 26, 2002.

3. APTA keeps up with the times by providing online education resources for its members. Available from http://www.apta.org/news/news_releases/news_archives/onlineeducation. Accessed on August 26, 2002.

4. Barr RB, Tagg J. From teaching to learning: A new paradigm for undergraduate education. Change. 1995; 27:13-25.

5. Billings D. Advantages and disadvantages of computer-assisted instruction. Dimensions in Critical Care Nursing. 1986;5:356-362.

6. Bloom BS. Taxonomy of educational objectives. Boston, MA: Allyn and Bacon; 1984.

7. Bukowski EL. Assessment outcomes: Computerized instruction in a human gross anatomy course. Journal of Allied Health. 2001;31:153-158.

8. Cheng-Chang P, Sivo S, Brophy J. Students' attitude in a web-enhanced hybrid course: A structural equation modeling inquiry. Journal of Educational Media \& Library Sciences. 2003; 41:181-194.

9. Davis FD. Perceived usefulness, perceived ease of use, and user acceptance of information technology. MIS Quarterly. 1989; 13:319-340.

10. Davis FD. User acceptance of information technology: system characteristics, user perceptions, and behavioral impacts. International Journal of Man Machine Studies. 1993; 38:475-487.

11. Education, CAPTE. Position Paper: Principles of good practice for distance learning: CAPTE. 2001.

12. English T, Harrison AL, Hart AL. A distance-learning model in a physical therapy curriculum. Journal of Allied Health. 1998; 27:228-232.

13. Erickson ML. Examining the presence of computer-assisted instruction in physical therapy education. Journal of Allied Health. 2003;33:255-266.

14. Fornaciari CJ, Forte M, Mathews CS. Distance Education as Strategy: How can your school compete? Journal of Management Education. 1999;23:703.

15. Foundation, Sloan C. Entering the mainstream: the quality and extent of online education in the United States. Available from http://www.sloan-c.org/publications/survey/survey04.asp. Accessed on November 17, 2004.

16. Furst-Bowe J, Dittman W. Identifying the needs of adult women in distance learning programs. International Journal of Instructional Media. 2001;4:405-413.

17. Gardiner L. Why we must change: The research evidence. Thought and Action. 1998;14:71-88.

18. Grimes PW, Willey TE. The effectiveness of microcomputer simulations in the principles of economics course. Computers \& Education. 1990;14:81-86.

19. Hirschheim R. The internet based education bandwagon: look before you leap. Communications of the ACM. 2005;48:97-101.

20. Hyland MR, Willis A. Prevalence of computer-assisted instruction in physical therapy programs within the United States. Unpublished Manuscript. 2004 
21. Jacoby C, Smith W, Albanese M. An evaluation of computer-assisted instruction in radiology. American Journal of Radiology. 1984;143:675-677.

22. Kinney P, Keskula D, Perry. The effects of a computer-assisted instructional program on physical therapy students. Journal of Allied Health. 1997;55:57-61.

23. Konukman F, Tacla C, Palmer S, Poole JR, Petrakis E. The effects of multimedia tennis computer-assisted instruction on tennis forehand, backhand knowledge, and psychomotor skills in a collegiate tennis basic instruction course. Research Quarterly for Exercise and Sport. 2001;72.1: A-69.

24. Kosmahl EM. Instructional use of computers for entry-level physical therapy education. Journal of Physical Therapy Education. 1984;8:25-31.

25. Lamperti A, Sodicoff M. Computer based neuroanatomy laboratory for medical students. The Anatomical Record. 1997;249:422-428.

26. Lilienfield LS, Broering NC. Computers as teachers: learning from animations. Advances in Physiology Education. 1994;11:547-554.

27. Phillips-Simpson B. Web-based and computer-assisted instruction in physical therapist education. Journal of Physical Therapy Education. 2002;17:45-49.

28. Plack M. Computer-assisted instruction versus traditional instruction in teaching human gross anatomy. Journal of Physical Therapy Education. 2000;14:38-43.

29. Rainbow SW, Sadler-Smith E. Attitudes to computer-assisted learning amongst business and management students. British Journal of Educational Technology. 2003;34:615-624.

30. Utsey C, Dillon L, Gleeson P. Designing and implementing an online clinical instructor certification course. APTA Combined Sections. New Orleans, La. 2003:Poster Presentation. 
NOTES 